\title{
PRE- AND POST-OPERATIVE ACETAZOLEAMIDE (DIAMOX) IN GLAUCOMA SURGERY*
}

\author{
BY \\ L. P. AGARWAL AND S. R. K. MALIK \\ Department of Ophthalmology, Medical College, Agra, United Provinces, India
}

ACETAZoleamide (Diamox) has been used to lower temporarily the intraocular pressure in eyes with raised tension (Becker, 1954; Agarwal and Saxena, 1955), in restoring flat chambers after intra-ocular operations (Murphy, 1954; Thrope, 1955a; Agarwal, Sharma, and Malik, 1955), as a pre-operative measure in cataract surgery to diminish the incidence of complications, and to complete the operation without iridectomy (Agarwal and Malik, 1957). Thorpe (1955b) used the drug as a prophylactic measure in glaucoma surgery, starting 4 to 6 hours after operation in six cases, and showed that acetazoleamide seemed to assist the early restoration and maintenance of the anterior chamber. He also concluded, however, that the lowered intra-ocular pressure might lead to minimal cystic filtration bleb formation in the surgical drainage area, and might therefore contraindicate its use. He says that the series is rather small to draw any tentative conclusions. The purpose of this paper is to report on the use of acetazoleamide as a prophylactic, beginning at least 2 days before operation.

\section{Material and Methods}

Fifty cases of glaucoma admitted to the wards of the S.N. Hospital, Agra, were chosen for this study.

All patients were given on admission, besides the routine treatment for glaucoma, a single daily dose of 500 to $1,000 \mathrm{mg}$. acetazoleamide, depending upon the initial level of the intra-ocular pressure. The treatment was continued for 2 to 3 days. One hour before operation the patient was given a tablet of $250 \mathrm{mg}$. and a delayedaction capsule of $250 \mathrm{mg}$. acetazoleamide. This dosage was continued for a week after operation. The patient was subjected to a post-placed valvular iridencleisis.

Fifty other cases were used as controls and received no acetazoleamide until the fifth post-operative day. If the chamber had not formed by then, acetazoleamide $250 \mathrm{mg}$. was given daily.

\section{Observations}

Records were maintained of the initial ocular tension, the tension at the time of operation, and the tension at the time of discharge. The incidence of flat chamber and the nature of the drainage bleb were also noted (Tables I to III, overleaf). Particularly in cases with high intra-ocular pressure, the administration of acetazoleamide lowered the tension and diminished the congestion, so enabling the surgeon to carry out the operative procedures with greater ease.

\footnotetext{
* Received for publication January 29, 1957.
} 
TABLE I

OCULAR TENSION IN PATIENTS AND CONTROLS

\begin{tabular}{c|c|c|c|c|c|c}
\hline \multirow{2}{*}{$\begin{array}{c}\text { Tension } \\
\text { (mm. Hg) }\end{array}$} & \multicolumn{2}{|c|}{ At Admission } & \multicolumn{2}{c|}{ At Operation } & \multicolumn{2}{c}{ At Discharge } \\
\cline { 2 - 7 } & No Diamox & Diamox & Controls & Series & Controls & Series \\
\hline Below 25 & nil & nil & nil & nil & 36 & 40 \\
25 to 30 & 4 & 3 & 6 & 25 & 10 & 8 \\
31 to 40 & 6 & 6 & 10 & 15 & 4 & 2 \\
41 to 50 & 14 & 13 & 15 & 8 & nil & nil \\
51 to 60 & 20 & 13 & 15 & 2 & nil & nil \\
Over 60 & 6 & 15 & 4 & nil & nil & nil \\
\hline
\end{tabular}

TABLE II

INCIDENCE OF FLAT CHAMBER

\begin{tabular}{|c|c|c|c|c|c|c|c|}
\hline \multirow{2}{*}{ Cases } & \multirow{2}{*}{ Number Treated } & \multicolumn{5}{|c|}{$\begin{array}{l}\text { Flat Chamber } \\
\text { (days) }\end{array}$} & \multirow{2}{*}{$\begin{array}{l}\text { Per cent. } \\
\text { Fifth Day }\end{array}$} \\
\hline & & 1 & 2 & 3 & 5 & 7 & \\
\hline No Diamox & 50 & 30 & 25 & 25 & $21 *$ & $4 \uparrow$ & 42 \\
\hline Diamox & 50 & 12 & 5 & 4 & $3 *$ & $2 \dagger$ & 6 \\
\hline
\end{tabular}

* Diamox given on this day.

$\dagger$ Air injected on this day.

TABLE III

ADEQUACY OF DRAINAGE

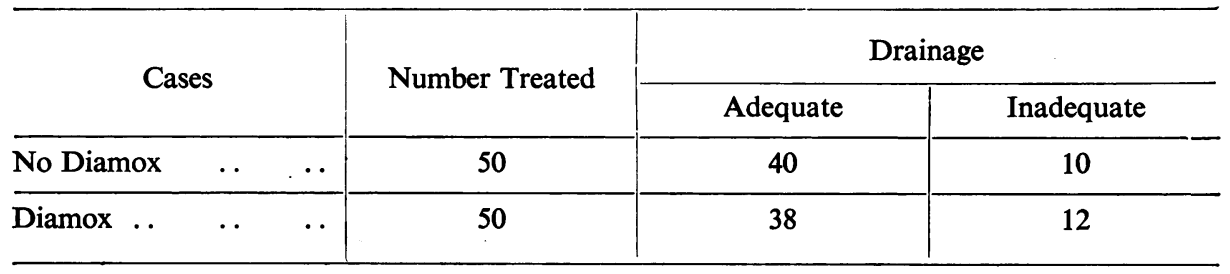

The incidence of flat chamber was considerably reduced (from 42 to 6 per cent.). The drainage bleb formed, though less cystic than in control cases, was adequate, and the drainage of aqueous humour was satisfactory.

\section{Discussion}

Acetazoleamide produces a certain degree of hypotension in glaucomatous eyes by the inhibition of the secretion of aqueous humour. Its pre-operative use assists glaucoma surgery. We have always felt that there is some risk in operating upon eyes with very high ocular tension. A valvular iridencleisis in itself obviates some of the dangers due to gradual decompression of the eyeball, and pre-operative acetazoleamide reduces these dangers still further. Mulberger and McDonald (1956) state that the pre-operative lowering of the intra-ocular pressure by miotics or other means makes operative procedures more difficult, but we have found the lowering of the intra-ocular pressure to near the normal level conducive to better results. 
We have already reported on the efficacy of this drug in the restoration of the anterior chamber after glaucoma surgery (Agarwal, Sharma, and Malik, 1955).

The incidence of flat chamber up to the fifth post-operative day in the control series of cases ( 42 per cent.) and in the cases in which acetazoleamide was given ( 6 per cent.) speaks for itself. Thorpe (1955a) suggested that the prophylactic use of this drug assisted early restoration and maintenance of the anterior chamber, but he did not rule out the possibility of spontaneous restoration. The present series indicates that the restoration of the anterior chamber is a definite result of pre- and post-operative acetazoleamide administration.

Thorpe (1955b) raised a doubt about the advisability of using the drug pre-operatively because of the risk of minimal cystic bleb formation and inadequate drainage. We followed up the results of iridencleisis in our test cases, and found that the bleb formed was not as cystic as in the control series, but the adequacy of drainage was never in doubt and the percentage of successes equalled that in the cases in which no acetazoleamide was given. It is said that iridencleisis is not a safe procedure in cases of glaucoma with high ocular tension, but post-placed valvular iridencleisis with early massage of the globe has been suggested (Agarwal, 1957) in such cases, and the use of acetazoleamide before and after the operation is of further assistance.

\section{Summary}

(1) Fifty cases of iridencleisis in which acetazoleamide was administered pre- and post-operatively form the basis of this study.

(2) The efficacy of this drug in the restoration of flat anterior chambers after glaucoma operations is confirmed, and its use in the prevention of flat chamber is suggested.

(3) Its pre-operative use in reducing intra-ocular pressure to facilitate iridencleisis, especially in patients with high ocular tension, is suggested.

(4) The fear of its adverse effect on drainage after glaucoma operations is discounted.

(5) Its routine use before and after glaucoma surgery is suggested.

We are grateful to Lederle Laboratories, Pearl River, New York, for the supply of Diamox (acetazoleamide).

\section{REFERENCES}

Agarwal, L. P. (1957). "Post-placed valvular iridencleisis". In press. and MALIK, S. R. K. (1957). Ophthalmologica (Basel). In press. and SAXENA, R. P. (1955). Ibid., 130, 164.

, ShaRma, K., and MALIK, S. R. K. (1955). British Journal of Ophthalmology, 39, 664.

BeCKer, B. (1954). Amer. J. Ophthal., 37, 13.

Mulberger, R. D., and McDonald, P. R. (1956). A.M.A. Arch. Ophthal., 55, 676.

MURPHY, E. U. (1955). Amer. J. Ophthal., 39, 86.

THORPE, H. E. (1955). "XVII Concilium Ophthalmologicum, 1954, Canada, U.S.A. Acta", vol. 3, p. 1855. University of Toronto Press. - (1955b). A.M.A. Arch. Ophthal., 54, 221. 